\title{
ULTRASONIC STUDIES IN BINARY LIQUID MIXTURES OF TRICHLOROETHYLENE WITH THREE ALCOHOLS AT 303.15 K
}

\author{
J. Panduranga Rao ${ }^{1, *}$, K. Jyothi ${ }^{2}$, K. Nanda Gopal ${ }^{3}$ and G. Srinivas ${ }^{4}$ \\ ${ }^{1}$ Department of Physics, KBN College Vijayawada, Andhra Pradesh, India \\ ${ }^{2}$ Department of Physics, Govt. College, Rajahmundry, Andhra Pradesh, India \\ ${ }^{3}$ India Meteorological Department, Kakinada, Andhra Pradesh, India \\ ${ }^{4}$ Department of Physics, Andhra Loyola College, Vijayawada, Andhra Pradesh, India \\ *E-mail: jpandu09@gmail.com
}

\begin{abstract}
Density $(\rho)$, ultrasonic velocities (u) and dynamic viscosity $(\eta)$ for three binary clusters of Trichloroethylene with 1pentanol, 1-hexanol and 1-heptanol are experimented at ambient temperature $303.15 \mathrm{~K}$ at atmospheric pressure over various compositions. The density and viscosity are calibrated using Specific gravity bottle and Ostwald's glass capillary viscometer respectively. The velocity is measured using ultrasonic interferometer. Molar volume, adiabatic compressibility, Intermolecular free length, and Wada's Constant are calculated using the above measured values. The excess parameters viz., excess molar volume, excess adiabatic compressibility, excess intermolecular free length, viscosity deviation are also deducted from experimental values. Intermolecular interactions, and structural interactions present in various mixture are discussed in detail.

Keywords: Ultrasonic velocity, Molecular viscosity, Molecular Interactions, Binary liquids, trichloroethylene
\end{abstract}

@ RASĀYAN. All rights reserved

\section{INTRODUCTION}

The physical and chemical properties of mixed liquids are influenced by the intermolecular forces..$^{1-5}$ Knowledge of density and viscosity is important in designing the processes involving chemical separations, equipment design, solution theory, heat transfer, fluid flow and molecular dynamics.

The research findings ${ }^{6-10}$ proved that the data on viscosity are useful for testing the theories and empirical relations of liquid mixtures. The study of the ultrasonic velocity in liquids and liquid mixtures and its influence on molecular structure were studied by several researchers. ${ }^{11-22}$ Ultrasonic studies in binary mixtures of hydrocarbon liquids with several alcohols were carried ${ }^{23-24}$ and observed, "Ultrasonic velocity has a parabolic variation with the composition of the mixture in several aqueous mixtures of alcohols". In many studies carried out ${ }^{25}$, it was observed that " the negative excess molar volume can be complimented to the strong interaction between unlike molecules through hydrogen bonding for the binary mixtures of 1,1,2,2-tetrabromoethane with 1-pentanol, 1-hexanol, 1-heptanol, 1-octanol and 1-decanol at the temperatures of 298.15 and $303.15 \mathrm{~K}$ and concluded that such a behavior is the result of several opposing effects. ${ }^{26}$ The variation of excess molar volume, deviation in viscosity and excess Gibb's free energy of binary mixtures of bromoform with anisole, acetophenone, ethyl benzoate, 1,2-dichloroethane and 1,2,2tetrachloroethane was studied earlier. ${ }^{27}$ The authors discussed compound values in terms of thermodynamic interactions involved between the binding components. In another study carried out ${ }^{28}$ in aqueous solutions of alcohols and amines, excess thermodynamic properties such as excess enthalpy and excess Gibb's free energy of flow were calculated and it was shown that these liquids also exhibit strong peaks at intermediate concentrations. ${ }^{29}$

The authors ${ }^{30}$ determined the ultrasonic velocity, density, viscosity experimentally and free volume, internal pressure were computed for the binary combination of n-butanol with aniline, n-methylaniline and n-dimethyl aniline. Excess free volume and excess internal pressures were deducted for these 
systems. The results were discussed in the wake of emerging theories of molecular interaction involved and the chemical constitution of the liquid components.

The literature survey on the ultrasonic studies as mentioned above indicates that though investigations on various properties of binary liquid mixtures have been carried out, not much work has been done on Trichloroethylene with alcohols. Therefore, detailed investigations on three binary liquid mixture, systems viz,

(1.) Trichloroethylene + 1-pentanol,

(2.) Trichloroethylene +1 -heptanol and

(3.) Trichloroethylene+ 1-hexanol

were undertaken to obtain reliable velocity, density and viscosity data at $303.15 \mathrm{~K}$ in the entire range of compositions. From these data, Molar volume (V), Excess molar volume $\left(\mathrm{V}^{\mathrm{E}}\right)$, Adiabatic compressibility $\left(\beta_{\mathrm{ad}}\right)$, Acoustic impedance $(\mathrm{Z})$, Deviation in adiabatic compressibility $\left(\Delta \beta_{\mathrm{ad}}\right)$, Intermolecular free length $\left(\mathrm{L}_{\mathrm{f}}\right)$ Excess intermolecular free length $\left(\Delta \mathrm{L}_{\mathrm{f}}^{\mathrm{E}}\right)$, Deviation in viscosity $(\Delta \eta)$, excess acoustic impedance $\left(Z^{\mathrm{E}}\right)$ Rao's Constant (R) Wada's Constant (W) were also calculated. The data ascertained was employed to understand intermolecular interactions between the unlike molecules and to test the theories of solutions.

\section{EXPERIMENTAL}

High purity and AR grade samples used in the present study were obtained from Merck Co. Inc., Germany. The liquids were distilled before use and mixed in the desired proportions using burette and are allowed to stay for 5 or 6 hours to attain thermal equilibrium before reading the experimental observations. Dissolved gases in the organic liquids are often a source of bubble formation, which introduces error in density measurements. In order to supersede the difficulty, all the liquids were degassed before taking readings. Variable path ultrasonic interferometer having a gold plated $\mathrm{x}-$ cut quartz crystal with a natural frequency of $2 \mathrm{MHz}$ with an accuracy of $\pm 0.1 \mathrm{~ms}^{-1}$ supplied by M/s Mittal enterprises ( model-05 F ), New Delhi (India), was used in the investigation. A digitally operated constant temperature bath to circulate water through the double walled measuring cell made of steel with a thermostat fixed with accuracy of $+0.05 \%$ was used to control the temperature. The densities of all the liquids and liquid mixtures have been measured using a $10 \mathrm{ml}$ specific gravity bottle. The weight of the solution was measured correct to $0.1 \mathrm{mg}$. by means of chemical balance. The viscosities have been determined by means of Ostwald's viscometer with an accuracy $0.001 \mathrm{Nm}^{-2} \mathrm{~s}$. The Viscometer was calibrated before use. The measurement of densities, viscosities and velocities for all the mixtures has been made at $303.15 \mathrm{~K}$. The time of flow of water and time of flow of solution were measured using digital stopwatch. In the entire experimental work, measurements have been made five times and the average values were taken into consideration to reduce the possible experimental error. The variation in the measurements is within an error of $0.1 \%$.

\section{Theory}

Excess Volume $\left(\mathbf{V}^{\mathbf{E}}\right)$ If $\mathrm{V}$ is the mean molar volume of a binary liquid combination. Excess molar volume is calculated using the relation:

$\mathrm{V}^{\mathrm{E}}=\mathrm{V}-\left(\mathrm{V}_{1} \mathrm{X}_{1}+\mathrm{V}_{2} \mathrm{X}_{2}\right)$

Where, $V_{1} V_{2}$ and $X_{1}, X_{2}$ are the molar volumes and the mole fractions of binary liquid mixture respectively.

Adiabatic Compressibility $\left(\boldsymbol{\beta}_{\mathbf{a d}}\right)$ Preconceiving that ultrasonic absorption is negligible, adiabatic compressibility can be arrived from the density and velocity of ultrasonic sound using the relation: $\beta_{\mathrm{ad}}=1 / \rho \mathrm{U}^{2}$

\section{Acoustic Impedance (Za)}

The specific acoustic impedance is: $\mathrm{Za}=\mathrm{U} \rho$ 


\section{RASĀYAN J. Chem.}

Vol. 10 | No. 2 | 488 - 498 | April - June | 2017

Deviation in adiabatic compressibility $\left(\Delta \boldsymbol{\beta}_{\mathrm{ad}}\right)$ at a given mole fraction is given by:

$\Delta \beta_{\text {ad }}=\beta_{\text {ad }}-\left(\beta_{\text {ad } 1} X_{1}+\beta_{\text {ad } 2} X_{2}\right)$

Where, $\beta_{\mathrm{ad} 1}$ and $\beta_{\mathrm{ad} 2}$ are the individual adiabatic compressibility values of pure liquids in the binary clusters at that temperature.

Intermolecular free length $\left(\mathbf{L}_{\mathbf{f}}\right)$ is obtained from the formula:

$\mathrm{L}_{\mathrm{f}}=\mathrm{K}\left(\beta_{\mathrm{ad}}\right)^{1 / 2}$

Where, $\mathrm{K}$ is Jacobson's constant.

Excess Intermolecular free length $\left(\mathbf{L}_{\mathbf{f}}^{\mathbf{E}}\right)$ has been determined as:

$\mathrm{L}_{\mathrm{f}}^{\mathrm{E}}=\mathrm{L}_{\mathrm{f}}-\left(\mathrm{L}_{\mathrm{f} 1} \mathrm{X}_{1}+\mathrm{L}_{\mathrm{f} 2} \mathrm{X}_{2}\right)$

Where, $\mathrm{L}_{\mathrm{f} 1}$ and $\mathrm{L}_{\mathrm{f} 2}$ are the isolated intermolecular free length values of pure liquids in the binary mixtures

Deviation in Viscosity $(\Delta \eta)$ is calculated by:

$\Delta \eta=\eta_{\text {mix }}-\left(X_{1 \eta 1}+X_{2 \eta 2}\right)$

Where, $\eta_{\text {mix }}, \eta_{1}$ and $\eta_{2}$ are the viscosities of the liquid combination and the individual values of pure liquids respectively.

Molar sound Velocity or Rao's constant $(\mathbf{R})$ are being calculated based on the following formula:

$\mathrm{R}=\mathrm{VU}^{1 / 3}$

Molar Compressibility or Wada's Constant $(\mathbf{W})$ has been calculated using formula: $\mathrm{W}=\mathrm{M} / \rho \mathrm{X} \beta_{\mathrm{ad}}{ }^{-1 / 7}$

Table-1: Comparison of experimental values of Density $(\rho)$, Viscosity $(\eta)$ and Ultrasonic Velocity (U) Values of pure liquids with literature values

\begin{tabular}{l|l|l|l|l|l|l}
\hline \multirow{2}{*}{ Component } & Density $(\mathrm{g} / \mathrm{cc})$ & \multicolumn{2}{l|}{ Viscosity(centipoise) } & \multicolumn{2}{l}{ Velocity (m/s) } \\
\cline { 2 - 7 } & Literature & $\begin{array}{l}\text { Experimenta } \\
1\end{array}$ & Literature & $\begin{array}{l}\text { Experimen } \\
\text { tal }\end{array}$ & Literature & $\begin{array}{l}\text { Experime } \\
\text { ntal }\end{array}$ \\
\hline $\begin{array}{l}\text { Trichloroethylene } \\
\text { (HCIC=CCICI): }\end{array}$ & 1.4556 & 1.4559 & 0.5362 & 0.5365 & 1015 & 1016 \\
\hline 1-Pentanol & 0.8086 & 0.8087 & 3.73 & 3.7309 & 1264 & 1264.5 \\
\hline 1-Hexanol & 0.81165 & 0.8117 & 4.683 & 4.6834 & 1273 & 1275.5 \\
\hline 1-Heptanol & 0.8149 & 0.8088 & 6.188 & 6.1778 & 1312 & 1316 \\
\hline
\end{tabular}

\section{RESULTS AND DISCUSSION}

The measured values of ultrasonic velocity $(U)$, density $(\rho)$, viscosity $(\eta)$ and computed values of deviation in viscosity $(\Delta \eta)$, molar volume $(\mathrm{V})$, excess molar volume $\left(\mathrm{V}^{\mathrm{E}}\right)$, adiabatic compressibility $\left(\beta_{\mathrm{ad}}\right)$, acoustic impedance $(\mathrm{Z})$, deviation in adiabatic compressibility $\left(\Delta \beta_{\mathrm{ad}}\right)$, intermolecular free length $\left(\mathrm{L}_{\mathrm{f}}\right)$, excess intermolecular free length $\left(\mathrm{L}_{\mathrm{f}}^{\mathrm{E}}\right)$, excess velocity $\left(\mathrm{U}^{\mathrm{E}}\right)$, excess acoustic impedance $\left(\mathrm{Z}^{\mathrm{E}}\right)$, Rao's constant (R) and Wada's constant (W) for the three binary liquid systems are presented in Tables2,3,4,5,6 and 7 respectively.

The deviation in ultrasonic velocity with the mole fraction of trichloroethylene for the three systems indicates that there is a non-linear decrease in velocity without having any minimum as shown in Fig.- 1 . The non-existence of maxima or dip at any intermediate concentration of trichloroethylene with 1pentanol, 1-hexanol and 1-heptanol indicate that there is no complex formation between components. These observations are in agreement with the general trends of the ultrasonic velocity variations in binary liquids $^{31-37}$.

The existence of structure differences in species in solution is bound to have its effect in the other physical parameters. In order to examine such possibilities, excess volumes of the cluster were calculated 
as function of composition. In the entire range of composition at $303.15 \mathrm{~K}$ the excess volumes for all the three systems were found to be negative, as shown in Fig.-2.

The data indicates that there exists a volume contraction in mixing and the negative excess volumes reach a minimum value at about 0.5 mole fraction of trichloroethylene. The three results indicate the closer approach of unlike molecules due to strong interaction ${ }^{38}$. The indication of excess volume $\left(\mathrm{V}^{\mathrm{E}}\right)$ of a system depends on the relative magnitude of expansion/contraction on mixing of two liquids. The $\mathrm{V}^{\mathrm{E}}$ becomes negative causing expansion and dominate the factors causing contraction, then $\mathrm{V}^{\mathrm{E}}$ becomes positive. On the other hand, if the contractive factors dominate the expansive factors, then $\mathrm{V}^{\mathrm{E}}$ becomes negative.

Table-2: System-1; Trichloroethylene + 1- Pentanol; Temperature - 303.15

\begin{tabular}{c|c|c|c|c|c|c|c|c|c}
\hline $\begin{array}{c}\text { Mole } \\
\text { fraction } \\
\mathrm{X}\end{array}$ & $\begin{array}{c}(\mathrm{U}) \\
\mathrm{m} / \mathrm{s}\end{array}$ & $\begin{array}{c}\rho \times 10^{-3} \\
\mathrm{~kg} / \mathrm{m}^{3}\end{array}$ & $\begin{array}{c}\eta \\
\mathrm{Cp}\end{array}$ & $\begin{array}{c}\mathrm{V}_{\mathrm{m}} \\
\mathrm{cm}^{-3} \mathrm{~mol}^{-1}\end{array}$ & $\begin{array}{c}\beta_{\mathrm{ad}} 10^{12} \\
\mathrm{~m}^{2} \mathrm{~N}^{-2}\end{array}$ & $\begin{array}{c}\mathrm{L}_{\mathrm{f}} \\
10^{-10} \mathrm{~m}\end{array}$ & $\mathrm{R}$ & $\mathrm{W}$ & $\mathrm{Z}$ \\
\hline 0.0000 & 1264.50 & 0.8087 & 3.7309 & 109.0021 & 77.3348 & 0.5514 & 5471 & 3034 & 1022.60 \\
0.1183 & 1235.20 & 0.8762 & 3.3869 & 106.4439 & 74.8034 & 0.5423 & 5301 & 2976 & 1082.28 \\
0.2319 & 1206.06 & 0.9435 & 3.0494 & 104.0522 & 72.8611 & 0.5352 & 5141 & 2921 & 1137.98 \\
0.3411 & 1178.31 & 1.0104 & 2.7161 & 101.8379 & 71.2828 & 0.5294 & 4993 & 2867 & 1190.58 \\
0.4460 & 1152.00 & 1.0774 & 2.3886 & 99.7162 & 69.9369 & 0.5243 & 4852 & 2815 & 1241.20 \\
0.5471 & 1127.35 & 1.1440 & 2.0684 & 97.7316 & 68.7792 & 0.5200 & 4721 & 2766 & 1289.69 \\
0.6443 & 1104.00 & 1.2088 & 1.7516 & 95.9690 & 67.8721 & 0.5166 & 4604 & 2721 & 1334.56 \\
0.7381 & 1082.28 & 1.2726 & 1.4384 & 94.3487 & 67.0869 & 0.5136 & 4496 & 2680 & 1377.28 \\
0.8285 & 1061.74 & 1.3357 & 1.1303 & 92.8129 & 66.4109 & 0.5110 & 4395 & 2640 & 1418.22 \\
0.9158 & 1041.09 & 1.3969 & 0.8292 & 91.4526 & 66.0491 & 0.5096 & 4302 & 2603 & 1454.27 \\
1.0000 & 1016.00 & 1.4559 & 0.5365 & 90.2466 & 66.5397 & 0.5115 & 4211 & 2566 & 1479.19 \\
\hline
\end{tabular}

Table-3: System-1; Trichloroethylene + 1- Pentanol; Temperature - 303.15k

\begin{tabular}{c|c|c|c|c|c|c}
\hline $\begin{array}{c}\text { Mole fraction } \\
\mathrm{X}\end{array}$ & $\begin{array}{c}\mathrm{V}_{\mathrm{m}}^{\mathrm{E}} \\
\mathrm{Cm}^{3} \mathrm{~mol}^{-1}\end{array}$ & $\begin{array}{c}\beta_{\mathrm{ad}^{\mathrm{E}}} 10^{10} \\
\mathrm{~m}^{2} \mathrm{~N}^{-1}\end{array}$ & $\begin{array}{c}\eta^{\mathrm{E}} \\
\mathrm{Cp}\end{array}$ & $\begin{array}{c}\mathrm{L}_{\mathrm{f}}^{\mathrm{E}} \\
10^{-10} \mathrm{~m}\end{array}$ & $\mathrm{U}^{\mathrm{E}}$ & $\mathrm{Z}^{\mathrm{E}}$ \\
\hline 0.0000 & 0.0000 & 0.0000 & 0.0000 & 0.0000 & 0.0000 & 0.0000 \\
0.1183 & -0.3390 & -1.2541 & 0.0340 & -0.0044 & 0.1034 & 5.6590 \\
0.2319 & -0.6000 & -1.9700 & 0.0594 & -0.0069 & -0.8046 & 9.4847 \\
0.3411 & -0.7670 & -2.3700 & 0.0748 & -0.0084 & -1.4349 & 12.2415 \\
0.4460 & -0.9200 & -2.5828 & 0.0826 & -0.0093 & -1.6566 & 14.9370 \\
0.5471 & -1.0100 & -2.6500 & 0.0850 & -0.0096 & -1.2056 & 17.3038 \\
0.6443 & -0.9480 & -2.5069 & 0.0790 & -0.0091 & -0.3795 & 17.7612 \\
0.7381 & -0.8100 & -2.2800 & 0.0653 & -0.0084 & 1.1985 & 17.6707 \\
0.8285 & -0.6500 & -1.9800 & 0.0460 & -0.0074 & 3.1240 & 17.3269 \\
0.9158 & -0.3740 & -1.4000 & 0.0236 & -0.0053 & 4.1565 & 13.5422 \\
1.0000 & 0.0000 & 0.0000 & 0.0000 & 0.0000 & 0.0000 & 0.0000 \\
\hline
\end{tabular}

Table-4: System-2; Trichloroethylene +1- Hexanol; Temperature $-303.15 \mathrm{~K}$

\begin{tabular}{c|c|c|c|c|c|c|c|c|c}
\hline $\begin{array}{c}\text { Mole fraction } \\
\mathrm{X}\end{array}$ & $\begin{array}{c}\mathrm{(U)} \\
\mathrm{m} / \mathrm{s}\end{array}$ & $\begin{array}{c}\rho \times 10^{-3} \\
\mathrm{~kg} / \mathrm{m}^{3}\end{array}$ & $\begin{array}{c}\eta \\
\mathrm{Cp}\end{array}$ & $\begin{array}{c}\mathrm{V}_{\mathrm{m}} \\
\mathrm{cm}^{-3} \mathrm{~mol}^{-1}\end{array}$ & $\begin{array}{c}\beta_{\text {ad }} 10^{12} \\
\mathrm{~m}^{2} \mathrm{~N}^{-2}\end{array}$ & $\begin{array}{c}\mathrm{L}_{\mathrm{f}} \\
10^{-10} \mathrm{~m}\end{array}$ & $\mathrm{R}$ & $\mathrm{W}$ & $\mathrm{Z}$ \\
\hline 0.0000 & 1275.5 & 0.8117 & 4.6834 & 125.8839 & 75.7257 & 0.5456 & 6337 & 3514 & 1035.32 \\
0.1342 & 1248.31 & 0.8792 & 4.1688 & 120.6817 & 72.9930 & 0.5357 & 6031 & 3386 & 1097.48 \\
0.2586 & 1219.40 & 0.9464 & 3.6798 & 115.9456 & 71.0606 & 0.5285 & 5750 & 3266 & 1154.05 \\
0.3741 & 1190.40 & 1.0135 & 3.2179 & 111.6024 & 69.6288 & 0.5232 & 5490 & 3153 & 1206.47 \\
\hline
\end{tabular}


RASĀYAN J. Chem.

Vol. 10 | No. 2 |488 - 498 | April - June | 2017

\begin{tabular}{l|l|l|l|l|l|l|l|l|l}
\hline 0.4818 & 1163.12 & 1.0801 & 2.7812 & 107.6382 & 68.4395 & 0.5187 & 5254 & 3048 & 1256.23 \\
0.5824 & 1137.27 & 1.1460 & 2.3671 & 104.0072 & 67.4654 & 0.5150 & 5039 & 2952 & 1303.33 \\
0.6766 & 1112.52 & 1.2111 & 1.9695 & 100.6860 & 66.7103 & 0.5121 & 4843 & 2862 & 1347.41 \\
0.7650 & 1089.06 & 1.2752 & 1.5900 & 97.6525 & 66.1187 & 0.5098 & 4663 & 2779 & 1388.75 \\
0.8480 & 1066.64 & 1.3379 & 1.2258 & 94.8880 & 65.6958 & 0.5082 & 4500 & 2703 & 1427.06 \\
0.9262 & 1044.25 & 1.3988 & 0.8755 & 92.3869 & 65.5574 & 0.5077 & 4351 & 2633 & 1460.74 \\
1.0000 & 1016.00 & 1.4559 & 0.5365 & 90.2466 & 66.5397 & 0.5115 & 4211 & 2566 & 1479.19 \\
\hline
\end{tabular}

Table-5: System-2; Trichloroethylene +1- Hexanol; Temperature - 303.15K

\begin{tabular}{c|c|c|c|c|c|c}
\hline $\begin{array}{c}\text { Mole fraction } \\
\mathrm{X}\end{array}$ & $\begin{array}{c}\mathrm{V}_{\mathrm{m}}^{\mathrm{E}} \\
\mathrm{Cm}^{3} \mathrm{~mol}^{-1}\end{array}$ & $\begin{array}{c}\beta_{\mathrm{ad}^{\mathrm{E}}} 10^{10} \\
\mathrm{~m}^{2} \mathrm{~N}^{-1}\end{array}$ & $\begin{array}{c}\eta^{\mathrm{E}} \\
\mathrm{cp}\end{array}$ & $\begin{array}{c}\mathrm{L}_{\mathrm{f}}^{\mathrm{E}} \\
10^{-10} \mathrm{~m}\end{array}$ & $\mathrm{U}^{\mathrm{E}}$ & $\mathrm{Z}^{\mathrm{E}}$ \\
\hline 0.0000 & 0.0000 & 0.0000 & 0.0000 & 0.0000 & 0.0000 & 0.0033 \\
0.1342 & -0.4200 & -1.5000 & 0.0419 & -0.0053 & 7.6339 & 2.5945 \\
0.2586 & -0.7240 & -2.2900 & 0.0686 & -0.0082 & 10.9928 & 3.9678 \\
0.3741 & -0.9480 & -2.6600 & 0.0860 & -0.0096 & 11.9939 & 5.0795 \\
0.4818 & -1.0740 & -2.8600 & 0.0960 & -0.0105 & 12.6593 & 7.0319 \\
0.5824 & -1.1200 & -2.9100 & 0.0990 & -0.0107 & 12.9191 & 9.4783 \\
0.6766 & -1.0850 & -2.8000 & 0.0920 & -0.0104 & 12.6029 & 11.7578 \\
0.7650 & -0.9700 & -2.5800 & 0.0788 & -0.0097 & 12.0691 & 13.8832 \\
0.8480 & -0.7750 & -2.2400 & 0.0590 & -0.0085 & 11.2035 & 15.3334 \\
0.9262 & -0.4890 & -1.6600 & 0.0330 & -0.0063 & 9.1038 & 14.3012 \\
1.0000 & 0.0000 & 0.0000 & 0.0000 & 0.0000 & 0.0000 & 0.0044 \\
\hline
\end{tabular}

Table-6: System-3: Trichloroethylene + 1- Heptanol; Temperature - 303.15K

\begin{tabular}{c|c|c|c|c|c|c}
\hline $\begin{array}{c}\text { Mole fraction } \\
\mathrm{X}\end{array}$ & $\begin{array}{c}\mathrm{V}_{\mathrm{m}}^{\mathrm{E}} \\
\mathrm{Cm}^{3} \mathrm{~mol}^{-1}\end{array}$ & $\begin{array}{c}\beta_{\mathrm{ad}^{\mathrm{E}} 10^{10}}^{\mathrm{m}^{2} \mathrm{~N}^{-1}} \\
0.0000\end{array}$ & $\begin{array}{c}\eta^{\mathrm{E}} \\
\mathrm{cp}\end{array}$ & $\begin{array}{c}\mathrm{Lf}_{\mathrm{E}}^{\mathrm{E}} \\
10^{-10} \mathrm{~m}\end{array}$ & $\mathrm{U}^{\mathrm{E}}$ & $\mathrm{Z}^{\mathrm{E}}$ \\
\hline 0.1503 & -0.5520 & -1.8000 & 0.0000 & 0.0000 & 0.0000 & 0.0008 \\
0.2847 & -0.9290 & -2.6700 & 0.0550 & -0.0067 & 15.8262 & 1.8443 \\
0.4056 & -1.1800 & -3.1300 & 0.1063 & -0.0101 & 22.9343 & 2.1806 \\
0.5149 & -1.3120 & -3.3500 & 0.1156 & -0.0128 & 26.1131 & 3.3609 \\
0.614 & -1.3700 & -3.4400 & 0.1188 & -0.0132 & 26.8954 & 9.2466 \\
0.7048 & -1.3400 & -3.3500 & 0.1100 & -0.0129 & 25.2217 & 12.9630 \\
0.7879 & -1.2310 & -3.0600 & 0.0956 & -0.0118 & 22.0408 & 15.9046 \\
0.8643 & -1.0400 & -2.6200 & 0.0739 & -0.0101 & 17.9595 & 18.0171 \\
0.9348 & -0.6800 & -1.9200 & 0.0425 & -0.0074 & 12.7193 & 16.9029 \\
1.0000 & 0.0000 & 0.0000 & 0.0000 & 0.0000 & 0.0000 & 0.0044 \\
\hline
\end{tabular}

The factors responsible for expansion in volume are as follows: ${ }^{39-40}$

1. Loss of dipolar association (i.e., Breaking up of associates held by weaker forces or rupturing of $\mathrm{H}$ - bonding of component by the other namely, dipole-dipole or dipole-induced dipole interactions or by Van der Waals forces).

2. The nature of molecular structure, which does not allow fitting of one component into other component.

3. Steric hindrance, opposes the proximity of the constituent molecules. The negative $\mathrm{V}^{\mathrm{E}}$ values arise due to the supremacy of the following factors:

i. Chemical interaction across constituent molecules, such as hetero molecular associations through the formation of $\mathrm{H}$-bond is known as strong specific interaction. 
ii. Accommodation of one kind of molecule component into the other interstitials of molecules with each other component.

iii. Nature of the molecular structure that favors fitting of the component molecules with each other.

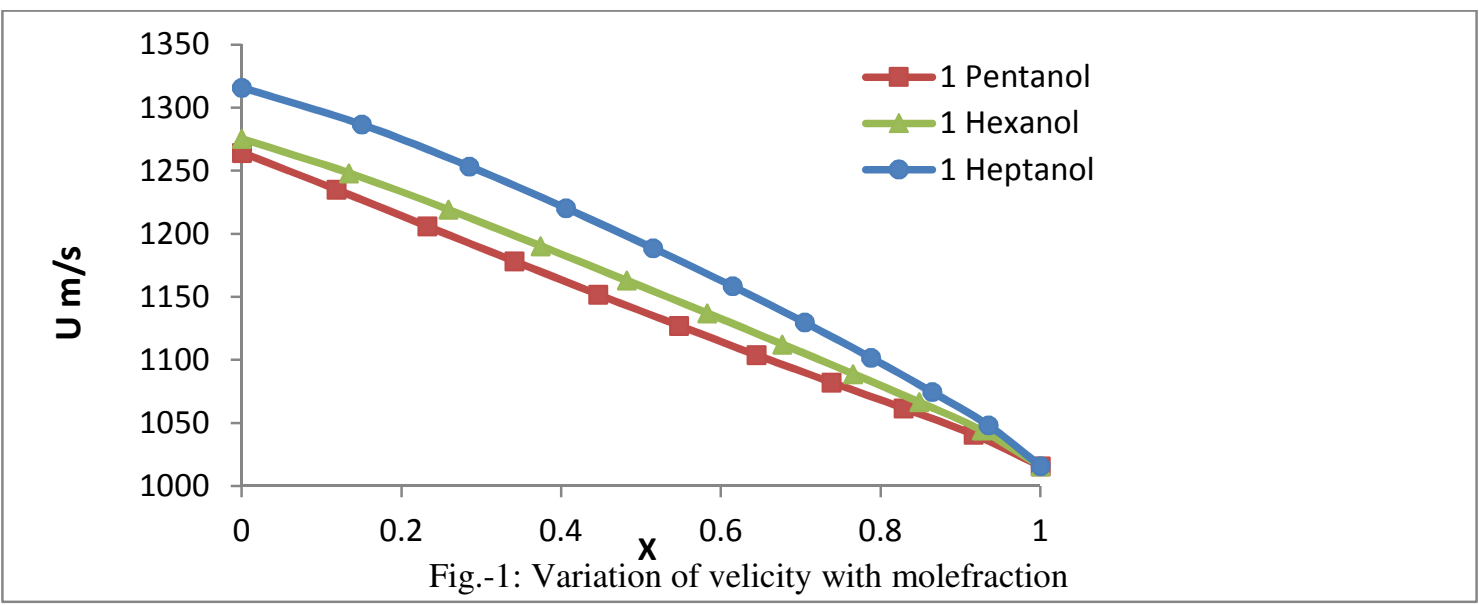

The excess volumes of all the three systems were found to be negative at the temperature studied indicates the existence of strong dipole-dipole interactions between the components. This is due to the dominance of the above mentioned factors responsible for contraction in volume.

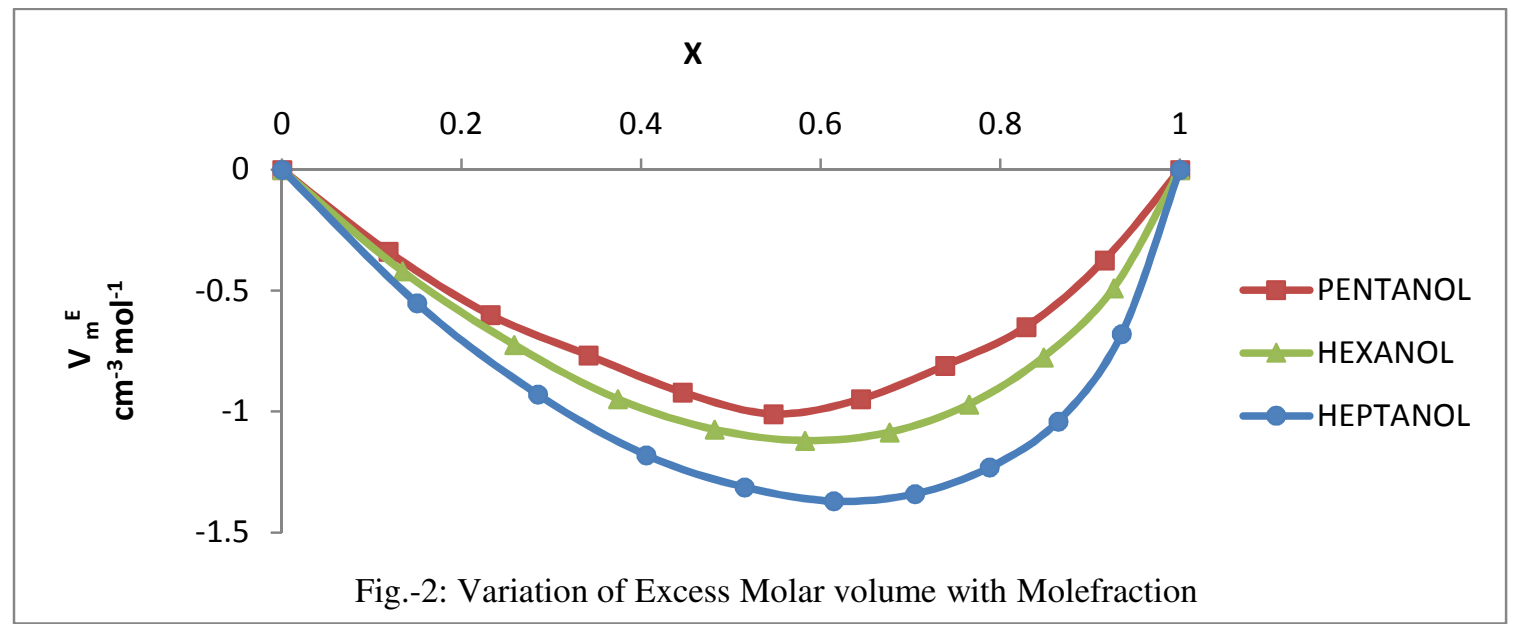

Several workers ${ }^{41-45}$ observed similar trends. This behavior is attributed mainly to the specific interactions between unlike molecules of the systems.

Another important parameter to understand the structural adjustment in solution due to molecular interactions is the intermolecular free length. The intermolecular free length $\left(\mathrm{L}_{\mathrm{f}}\right)$, adiabatic compressibility $\left(\beta_{\mathrm{ad}}\right)$ have inverse relationship with ultrasonic velocity (U) shown in Figures-3 and 4. Presence of maxima $U$ and minima in $\beta a d$ and $L_{f}$ at the same concentrations indicate strong interaction through the formation of hydrogen-bonding and dipole-dipole interactions between the components. ${ }^{46}$

For all the three systems the linear free length decreases with increases in the mole fraction of trichloroethylene. At an intermediate composition for all three systems the variation of excess free length with mole fraction Fig.-3 indicates that there exists a broad minimum in excess free length. In case of all the systems studied, the minimum value is obtained at about 0.5 mole fraction of trichloroethylene. The 
negative excess mean free length for all the three systems in the entire range of compositions also indicates the existence of strong interaction between the components. ${ }^{47}$

Deviations in adiabatic compressibility can be explained in terms of its contributions made by the following factors:

(a) The difference in size and shape of the component molecule leads to decrease in sound velocity and increase in adiabatic compressibility and

(b) A decrease in free lengths as a result of dipole-dipole interactions or hydrogen bonded complex formation between unlike molecules leads to decrease of sound velocity and increase of compressibility.

The experimental values of deviations in compressibility in all the three systems at an intermediate composition are negative (Fig.-4).Negative deviations in compressibility indicates strong molecular interactions in liquid mixtures while positive sign is an indication of weak interactions due to dispersion forces. The negative deviation in compressibility for all the three systems studied indicate the existence of strong interaction between the unlike molecules. ${ }^{48-49}$

The diversity in viscosity $(\Delta \eta)$ gives a quantitative estimate of intermolecular interactions. The $\Delta \eta$ at each composition is obtained from the relation suggested by Fort and Moore ${ }^{50}$. The diversity in viscosity becomes positive as the strength of interaction increases. The $\Delta \eta$ values may be generally explained considering on the following factors: ${ }^{51-54}$

1. The differences in the size and shape of the component molecules and the loss in dipolar interactions in pure components may contribute to a decrease in viscosity.

2. The specific interactions between unlike molecules in hydrogen bond formation and charge transfer complex may lead to increase in viscosity in combinations than in pure components.

The later effect introduces positive deviation while the former effect produces negative deviation in viscosity. The net deviation in viscosity is generally considered as a result of the two major effects. The deviations in viscosity for the three systems at the temperature $(303.15 \mathrm{~K})$ are negative indicating the dominance of nonspecific interactions between unlike molecules.

The experimental values of viscosities as a function of mole fraction of trichloroethylene for three systems are shown in Fig-5. The three systems exhibit a positive deviation of excess viscosity over entire mole fraction range with a maximum corresponding to a mole fraction of about 0.5 at the temperature studied. These deviations indicate specific molecular interactions between different molecules.

The variation in the size of the molecules will influence the intermolecular forces therefore the excess thermodynamic properties will be effected. ${ }^{55-56}$ An increase in the values of $\mathrm{Z}$ with the mole fraction of trichloroethylene for all the combinations shows the presence of specific interactions between unlike molecules. ${ }^{57-60}$ The negative or positive deviations in $\mathrm{Z}^{\mathrm{E}}$ and $\mathrm{U}^{\mathrm{E}}$ from rectilinear dependence on composition of the mixtures indicate the extent of association or dissociation between unlike molecules and these are represented in Tables-3, 5 and 7 respectively for all the three systems studied over the entire range of combination at $303.15 \mathrm{~K}$. Positive deviations indicate the increase in strengthen of interaction between component molecules of the liquid mixtures. ${ }^{61-64}$. The positive deviations in ultrasonic velocity can be interpreted in two opposing effects ${ }^{65}$ as:

i. $\quad$ Components exert a mutual structure- breaking effect on mixing.

ii. Hydrogen bond interactions between unlike molecules.

The first effect contributes to an increase in the free length, leading to a negative deviation in the speed of sound and the latter effect contributes to a positive deviation in the speed of sound. ${ }^{62}$ The sign and magnitude of the actual deviation depend on the relative strengths of the two effects. The experimental values of $\mathrm{U}^{\mathrm{E}}$ focus that the latter effect dominates in all the three systems. From the above stated conclusion, it is clear that there is a strong association between unlike molecules in the liquid combinations and this interaction may be accompanied by the disruption of the structure of the components. 
RASĀYAN J. Chem.

Vol. 10 | No. 2 | 488 - 498 | April - June | 2017

Table-7: System-3; Trichloroethylene + 1- Heptanol; Temperature - 308.15K

\begin{tabular}{c|c|c|c|c|c|c|c|c|c}
\hline $\begin{array}{c}\text { Mole } \\
\text { fraction } \\
\mathrm{X}\end{array}$ & $\begin{array}{c}\mathrm{(U)} \\
\mathrm{m} / \mathrm{s}\end{array}$ & $\begin{array}{c}\rho \times 10^{-3} \\
\mathrm{~kg} / \mathrm{m}^{3}\end{array}$ & $\begin{array}{c}\eta \\
\mathrm{Cp}\end{array}$ & $\begin{array}{c}\mathrm{V}_{\mathrm{m}} \\
\mathrm{cm}^{-3} \mathrm{~mol}^{-1}\end{array}$ & $\begin{array}{c}\beta_{\mathrm{ad}} 10^{12} \\
\mathrm{~m}^{2} \mathrm{~N}^{-2}\end{array}$ & $\begin{array}{c}\mathrm{L}_{\mathrm{f}} \\
10^{-10} \mathrm{~m}\end{array}$ & $\mathrm{R}$ & $\mathrm{W}$ & $\mathrm{Z}$ \\
\hline 0.0000 & 1316.00 & 0.8088 & 6.1778 & 143.6696 & 71.3916 & 0.5298 & 7308 & 4044 & 1064.38 \\
0.1503 & 1286.74 & 0.8771 & 5.3849 & 135.0881 & 68.8624 & 0.5203 & 6820 & 3822 & 1128.57 \\
0.2847 & 1253.53 & 0.9451 & 4.6593 & 127.5317 & 67.3403 & 0.5145 & 6383 & 3620 & 1184.65 \\
0.4056 & 1220.44 & 1.0127 & 3.9962 & 120.8231 & 66.2938 & 0.5105 & 5993 & 3437 & 1235.97 \\
0.5149 & 1188.66 & 1.0798 & 3.3889 & 114.8516 & 65.5435 & 0.5076 & 5647 & 3273 & 1283.55 \\
0.6142 & 1158.64 & 1.1465 & 2.8318 & 109.4876 & 64.9716 & 0.5054 & 5338 & 3124 & 1328.40 \\
0.7048 & 1129.77 & 1.2124 & 2.3116 & 104.6751 & 64.6218 & 0.5040 & 5060 & 2989 & 1369.72 \\
0.7879 & 1101.67 & 1.2772 & 1.8287 & 100.3470 & 64.5088 & 0.5036 & 4810 & 2866 & 1407.11 \\
0.8643 & 1074.68 & 1.3408 & 1.3761 & 96.4574 & 64.5782 & 0.5039 & 4586 & 2754 & 1440.91 \\
0.9348 & 1048.29 & 1.4014 & 0.9470 & 93.0520 & 64.9362 & 0.5053 & 4388 & 2655 & 1469.03 \\
1.0000 & 1016.00 & 1.4559 & 0.5365 & 90.2466 & 66.5397 & 0.5115 & 4211 & 2566 & 1479.19 \\
\hline
\end{tabular}
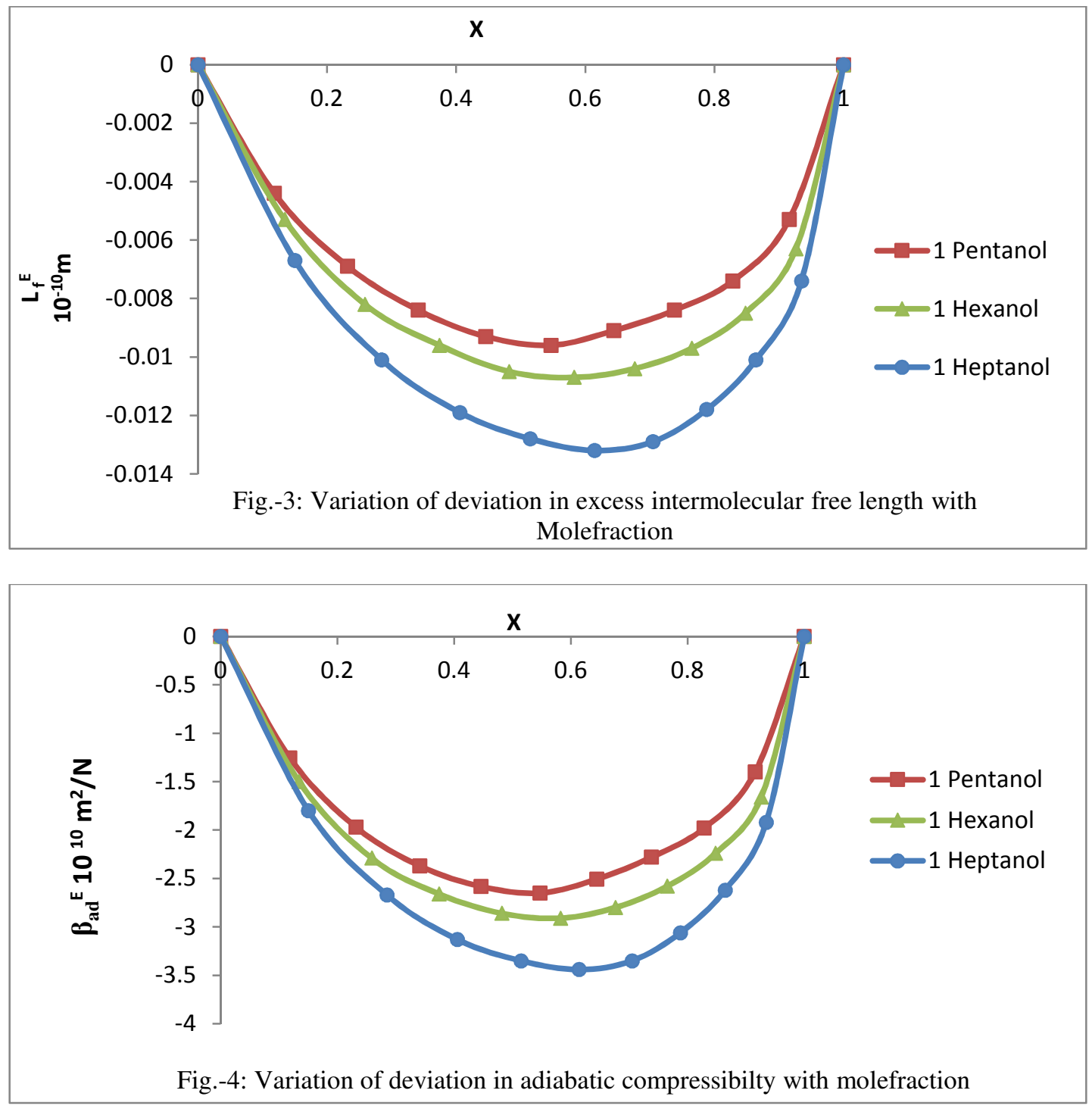


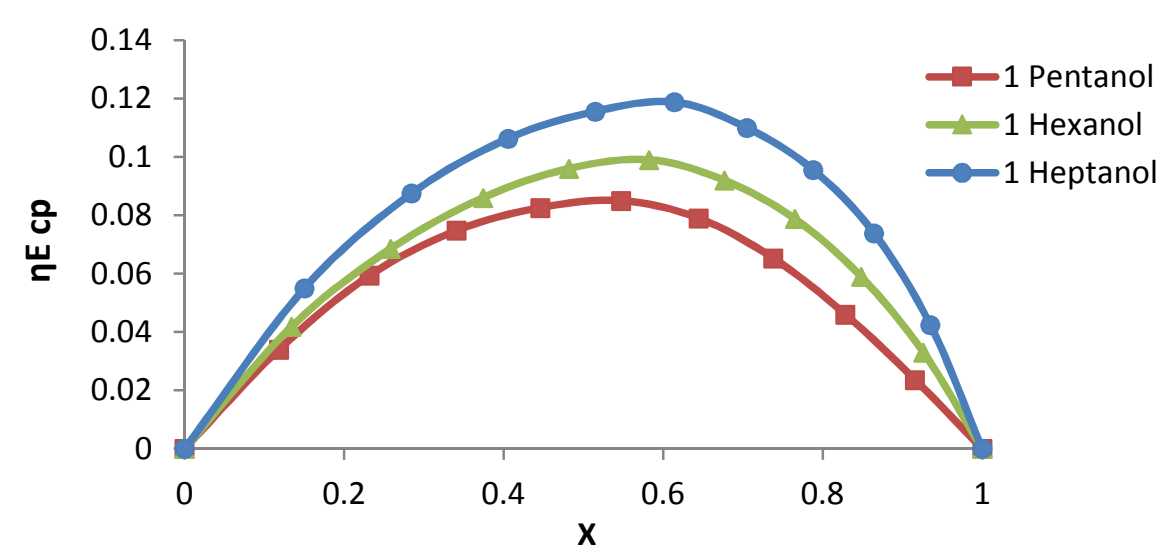

Fig.-5: Variation of deviation in viscocity with molefraction

Strong interactions arise among the components of a liquid combination leading to formation of molecular aggregates and more compact structures leading to the sound waves to travel faster through the combination and therefore the speed of sound deviations will be positive. On the other hand, if the predominant effect in the combination is structure breaking and results in expansion, the speed of sound through the combination will be slower and the deviation will be negative. ${ }^{65}$ In the present study the excess ultrasonic velocity of all binary clusters are positive which indicate that structure making effect is predominant. ${ }^{66-67}$

\section{CONCLUSION}

In this work, we have measured density, viscosity and velocity of sound using binary clusters of trichloroethylene with 1-pentanol, 1-hexanol and 1-heptanol at the temperature 303.15K. Deviations in speed of sound, excess molar volume, viscosity, adiabatic compressibility, excess free length and acoustic impedance are calculated. The deviation in viscosity and acoustic impedance show positive behavior, while excess molar volume, deviation in adiabatic compressibility and excess free length show negative behavior for the systems under investigation indicating strong interactions between the components. However, the deviation in sound showed positive trend.

\section{ACKNOWLEDGEMENT}

One of the authors (J. Panduranga Rao) is thankful to UGC for the financial assistance for the minor research project with title "Ultrasonic studies on Binary liquid mixtures of trichloro ethylene with three alcohols at 303.15 K” Ref. No. MRP -5926/15 (MRP/UGC-SERO) Dtd: 13.01.2015.

\section{REFERENCES}

1. P. Deepali, M. L. GulwadeNarwade and K. N. Wadodkar, Indian J. Chem., 43A, 2102 (2004).

2. J. Galka, L. Suaki and K. P. Tomczy, J. Chem.Thermodyn., 9, 673 (1997).

3. V. Kannappan and Jaya Santhi, Indian J. Pure Appl.Phys., 43, 750 (2005).

4. M. F. Bolotnikov, Y. A. Neruchev, Melikhov, V. N. Verveyko and M. V. Verveyko, J. ChemEng. Data, 50, 1095(2005).

5. C. Valles, E. Perez, A. M. Mainar, J. Santafe and M. Dominguez, J. ChemEng. Data, 51, 1105 (2006).

6. L. Grunberg and A. H. Nissan, Nature, 164, 799 (1949).

7. M. Tamura and M. Kurata, Bull. ChemSoc. Japan, 25, 32 (1952).

8. R. K. Hind, E. Mc. Laughlin and A.R. Ubbelohde, Trans. Faraday Soc., 56, 328 (1960).

9. P. K. Katti and M. M. Chaudhri, J. ChemEng. Data, 9, 442 (1942).

10. E.L. Heric, J. ChermEng. Data, 11, (1996/66).

11. S. Parthasarathy, Proc.Ind. Acad.So.c, 2497, 3285 (1935). 
RASĀYAN J. Chem.

Vol. 10 | No. 2 | 488 - 498 | April - June | 2017

12. R. Prasad, Indian J. Phys., 19, 47 (1945).

13. A. Weissler, J. Chem.Phys., 15, 210 (1947).

14. E. Seet, Zeits.Naturfursch, 59, 559 (1964).

15. K.C. Reddy, J. Phys.Soc., Japan, 19, 559 (1964).

16. R.J. Fort and W R Moore, Trans Faraday Soc., 61, 2101 (1965).

17. M.T. Zafarani-Moattar and S. Sarmad, J. ChemEng. Data, 50, 283 (2005).

18. B. Gonzalez, A .Dominguez and J. Tojo, J. ChemEng. Data, 51, 1076 (2006).

19. C. M Kinart, W.J. Kinart and Checinska- D Majak, J. ChemEng. Data, 48, 1037 (2003).

20. D.S. Wankhede, M. K. Lande and B R Arbad, J. ChemEng. Data, 50, 261 (2003).

21. M.I. Aralaguppi and J. G. Baragi, J. Chem.Thermodyn., 38, 434 (2006).

22. B. Gonzalez, A. Dominguez and J. Tojo, J. Chem.Thermodyn., 38, 07 (2006).

23. F. Danusso, RC. Acd. Nas. Lincei., 17, 114, 234(1954).

24. G.W. Willard, J. Acoust.Soc.Am., 9, 223 (1947).

25. M.N.M. Al-Hayam and M. A. M. Al-Baer, J. Chem.Thermodyn, 38, 1100 (2006).

26. A.J. Treszczanowicz, O. Kiyohara and G. C. Benson, J. Chem.Thermodyn, 13, 253 (1981).

27. S.S.S. Srikanth, Joshi, T.M Aminabhavi and S.S Shukla, Indian J. Tech., 29, 319 (1991).

28. T.H. Aminabhavi and L.S. Manjaeshwar, Indian J. Chem., 27A, 1721 (1988).

29. G. Felix and L. Huyskons, J. Phys.Chem., 79, 2316 (1975).

30. N. Prasad and R. P. K. Ray, J. Pure Appl. Ultrason., 30, 31 (2008).

31. M. M. H. Bhuiyan, and M. H. Uddin, J. Mol. Liquid, 138, 139 (2008).

32. M. V. Rathnam and SudhirMohite, J. ChemEng. Data, 50, 325 (2005).

33. H. Wang, W. Liu and Wu Y, J. Chem.Thermodyn, 36, 1079 (2004).

34. Rita Mehra and A.K Gaur, J. Indian Council Chem, 26(1), 85 (2009).

35. R.C. Katyal, S. Sing , V. K. Rattan, K. Pawan and S. Acharya, J. ChemEng. Data,48 , 1262 (2003).

36. B. Rangith Kumar, S. AsraBanu, K. Amara Jyothi, T.S. Jyostna and N. Satyanarayana, Indian J. Pure and Appl. Phys.,47, 511 (2009).

37. M.I. Aralaguppi and J. G. Baragi, J. Chem.Thermodyn., 38, 434 (2006).

38. J. Veeraswamy and N. Satyanarayana, Rasayan J. Chem., 1, 602-608 (2008).

39. V. Syamala, P. Venkateswarlu and K. Siva Kumar, J. Chem.Eng. Data, 51, 928 (2006).

40. D. Papamatthaiakis, FryniAroni and V. Havredaki, J. Chem. Thermodynamics, 40 (2008)107.

41. Haijun Wang, Wei Liu and Yonghua Wu, J. Chem. Thermodynamics, 36, 1079 (2004).

42. N. G. Tsierkezos, L E Molinou and A.C. Fillippou, J. Sol. Chem., 34, 1371 (2005).

43. R. Uvarani and J. Siva Pragasam, E- Journal of Chemistry, 6(4) 1150 (2009).

44. N. G Tsierkezos and L. E Molinou, Phys.Chem. Liquids, 47, 172 (2009).

45. L. Moravkova and J. Linek, J. Chem.Thermodyn., 37, 814 (2005).

46. V.K. Syal, U. Kumari, S. Chauhan and M.S. Chauhan, Indian J. Pure Appl.Phy., 30, 719 (1992).

47. S.J. Tangeda, S. boodidasnallani, J. Chem. Thermodyn., 38, 1438 (2006).

48. H. Iloukhani and Z. B. Nojini, Phys.Chem.Liq., 43, 429 (2005).

49. O. Kiyohara and G. C. Benson, J. Chem.Thermodyn., 11, 861 (1979).

50. R.J Fort and W.H Moore, Trans. Faraday Soc., 61, 2102 (1965).

51. S.S Joshi, Indian J. Tech., 29, 541 (1991).

52. T.M. Aminabhavi and R.H. Balundgi, Indian J. Tech., 29, 385 (1981).

53. R. Nigam D.S. K. and Mahal, Indian J. Chem., 9A, 1225 (1971).

54. G.C. Benson, P. J. D.' Arey and Y. P. Handa, Thermo. Chem. Acta, 46, 295 (1981).

55. M.N. Islam, M.A. Ali, M.M Islam and M.K. Nahar, Phys.Chem.Liq., 41(3), 271 (2003).

56. S.S. Joshi, T.M Aminabhavi, R Balundgi and S.S Shukla, Indian J. Tech., 29, 42 (1991).

57. D.S. Wankhede, N. N. Wankhede, M.K. Lande and B.R. Arbad, Indian J. Pure Appl.Phys., 44, 909 (2006).

58. M.F. Bolotnikov, Y.A. Neruchev, Y.F. Melikhov, V.N. Verveyko and M.V. Verveyko, J. Chem. Eng. Data, 50, 1095 (2005). 
RASĀYAN J. Chem.

Vol. 10 | No. 2 |488 - 498 | April - June | 2017

59. T.S. Jyostna and T. Satyanarayana, Indian J. Pure Appl.Phys., 43, 591 (2005).

60. A. Pal and Anil Kumar. Indian J. Phys., 78 (12), 1319 (2004).

61. D.S Wankhede, N.N. Wankhede, M.K. Lande and B.R. Arbad, Indian J. Pure Appl.Phys, 44, 909 (2006).

62. M.F. Bolotnikov, Y.A. Neruchev, Y.F. Melikhov, V.N. Verveyko and M.V. Verveyko, J. Chem. Eng. Data, 50, 1095 (2005).

63. T.S. Jyostna and T. Satyanarayana, Indian J. pure ApplPhys, 43, 591 (2005).

64. A. Pal and Anil Kumar, Indian J. Phys, 78 (12), 1319 (2004).

65. T.J. Savitha and N. Satyanarayana, J. Chem.Eng. Data, 50, 89 (2005).

66. F. Vesely, P. Uchytil, M. Zabransky, J Pick, Collect Czech Chem.Commun., 44, 2869 (1979).

67. K.C. Singh, K.C. Karla, S. Maken and V. Gupta, fluid Phase Equilib., 123, 271 (1996).

[RJC-1610/2017] 